\title{
O SABER E OS CENTROS DE SABER NAS SETE PARTIDAS DE ALFONSO X O SÁBIO
}

Maria Guadalupe Pedrero-Sánchez*

SÍNTESE - O periodo medieval é longo e de grande efervescência. Nele o saber foi se desenvolvendo e organizando aos poucos, acentuandose sempre mais a importância da natureza. A partir do século XII, organizam-se escolas, no século XIII, as universidades. Nas "Siete Partidas" o rei Alfonso X idealiza e define o que seria o studium generale.

PALAVRAS-CHAVE - conhecimento, organização do saber, universidade, studium generale, "Siete Partidas".
ABSTRACT - Long time has lasted the medieval period with characteristics of a great effervescence. Slow was the development and the organization of the knowledge. However the importance of the nature was more and more enhanced. Schools are organized in the twelfth century and in the next century are founded the universities. The king Alfonso $\mathrm{X}$ idealizes and defines in the "Siete Partidas" what would be the studium generale.

KEY WORDS - knowledge, organization of the knowledge, university, studium generale, "Siete Partidas".

Durante a Idade Média, a república das letras conhece auroras e crepúsculos, a face do mundo transformava-se muito mais do que podemos imaginar e o mito de um mundo unitário e fechado em si mesmo cede diante da evidência; a primeira característica desta época é o confronto que teve de manter contra o que poderíamos chamar as múltiplas facetas do outro: terras, idéias, povos, maneiras de viver e de sentir. Da época carolíngia até o fim do século XIII, transcorrem quase seis séculos de uma história rica em episódios de miséria e de glória. Ao longo destes anos o Império e a Cristandade vão se construindo entre sobressaltos políticos ou bélicos; surgem, desenvolvem-se e desaparecem movimentos culturais ou religiosos, vinculados a novas leituras do passado abrindo-se corajosamente ao futuro; aparecem novas formas de civilização, formas inéditas de olhar o homem e o mundo, maneiras desconhecidas de dirigir os recursos.

* Departamento de História. Faculdade de Ciências e Letras - FCL de Assis. Universidade Estadual Paulista - UNESP.

\begin{tabular}{|l|l|l|l|l|l|}
\hline VERITAS & Porto Alegre & v. 43 & $\mathrm{n}^{2} 3$ & Setembro 1998 & p. 577-592 \\
\hline
\end{tabular}


O entravado social vai diversificando-se. Nascem novas classes sociais: nobres e clérigos, camponeses, monges de todas as ordens e inspirações, sábios e mestres, comentadores e copistas, criadores de ciência e multiplicadores do saber e homens de negócios, num clima de intercâmbios culturais e comerciais. Todos estes grupos não foram nunca grupos estanques, entre outras coisas porque a sociedade civil e politica tampouco o era. As fronteiras deslocam-se, as áreas de influência se redefinem, as ortodoxias de todo tipo - temporais e espirituais traçam linhas de pertença e exclusão que, uma vez estabelecidas, são criticadas e substituídas por outras.

Estas mudanças manifestam-se nitidamente nas novas formas de pensamento e nas descobertas que ele faz possivel no campo da cultura, sem deixar de considerar as dificeis relações entre o Ocidente latino e o Oriente próximo, que supôs o confronto definitivo, primeiro entre Atenas-Roma e Jerusalém, segundo entre Roma e Atenas-Constantinopla e em terceiro lugar entre Roma-Constantinopla e Bagdad.

A historiografia trata de destacar alguns dos momentos significativos desse processo que receberam, às vezes, a denominação de renascimentos. ${ }^{1}$ Uma questão de fundo com plena vigência pode ser a seguinte: houve continuidade neste processo? A possibiiidade de localizar momentos chaves e significativos não implica uma ruptura absoluta, a identificação dos diversos "renascimentos" na Idade Média, vem sempre acompanhada de uma matização especial ao utilizar esta expressão, porém a consciência de continuidade dos próprios protagonistas permanece forte e nítida.

A experiência carolíngia, que corre paralela ao confronto entre RomaConstantinopla, tem as suas bases culturais na realização de reformas politicas, administrativas e religiosas. A infra-estrutura deste "renascimento" é buscada entre os continuadores da tradição romano-germânica. Entre os lombardos e a tradição de Boécio: Pedro de Pisa; entre os anglo-saxões, a tradição do monaquismo irlandếs e Beda: Alcuíno; entre os visigodos e a tradição de Isidoro de Sevilla: Teodulfo, entre outros. Uma das realizações que materializa esta tentativa renovadora é a criação de escolas, nas quais se afirma o sistema do trivium e do quadrivium. Escolas muito restritas, porque o interesse imediato frisa, principalmente, a elevação cultural do clero para servir às próprias exigências de uma restruturação político-administrativa unificada. Nelas o latim se instala como a língua do saber, afirmando-se, também, o bilingüismo que reforça a identificação dos clérigos como cultos e dos leigos como analfabetos. Por esta via "a Igreja assegura-se o monopólio da cultura que deterá durante muito tempo". 2

O saldo mais positivo vem marcado pelo entesouramento de manuscritos, obra dos copistas, cujo destaque está no seu papel de multiplicadores, assim como pelo despertar para a busca de novas fontes propiciando o trabalho isolado de sábios que não deixaram de aproveitar a porta aberta ao saber, tais como João

1 Entre outros RABADE, S. Los renacimientos de la filosofia medieval. Madrid: Arco-libros, 1997. LABORRIERE, P-J De la Europa Carolingia a la era de Dante. Madrid: Akal, 1997.

2

LABORRIERE, P-J, Ibidem. p. 12. 
Escoto Erigena, Eginardo ou Hicmar de Reims. Nesse mesmo caminho, além da função unificadora da reforma gregoriana situa-se o labor das Ordens monásticas: Cluny e Citeaux.

É no século XI quando se edifica e consolida, política e religiosamente o que se denomina Cristandade, não sem lutas internas entre os poderes públicos e as instâncias eclesiásticas no seu mais alto nivel: o Papado e o Império; momento que coincide, também, com a modificação da paisagem social: da terra e dos bens raizes à posse do dinheiro, do campo para a cidade.

O confronto entre o Papado e o Império alinha pensadores e teóricos que escrevem para justificar um ou outro posicionamento e marca duas matrizes: o espaço dos monges e o espaço do clero regular, é a época das catedrais. Um saldo positivo do confronto entre Igreja-Estado está marcado pelo impulso que, direta e indiretamente, recebe o Direito, tanto canônico como civil.

Será no espaço citadino onde se dá o terceiro confronto a que nos referíamos: Roma - Constantinopla frente a Bagdad; porque após as Cruzadas, independente do êxito ou do fracasso dos seus objetivos concretos, abriram-se, colateralmente, novos caminhos de intercâmbio, tanto comerciais como culturais.

O segundo "renascimento" apontado pela historiografia acontecerá no século XII, o seu desenvolvimento não se restringe agora a individuos isolados, mas a "centros de saber". É o momento das escolas capitulares ou catedralícias, entre as que ocupam um lugar de destaque: Chartres e Paris.

A consciência de continuidade tanto como a de renovação é clara, os conceitos de "antigos" e "modernos" têm a sua expressão paradigmática nas palavras de Bernardo de Chartres que tanta ressonância tiveram na Idade Média "somos como anões subidos nos ombros de gigantes". ${ }^{3}$ Estes centros adquirem uma certa emancipação social e intelectual e até uma certa alegria de viver.

$O$ elemento novo e renovador será a reflexão sobre o homem - o humanismo com uma perspectiva não só metafísica. Nas Bibliotecas dos novos centros continuam a ser encontrados Capella, Prisciano, Boécio, Isidoro de Sevilla, Agostinho mas também Horácio, Cícero, Ovídio, Lucano, Marcial e Virgílio.

Entre os problemas fundamentais do pensamento do século XII ao XIII podem ser identificados os temas seguintes: o dos universais: individuo ou individuação?; o da Natureza, criada por Deus, sim, mas também considerada em si mesma; o da Liberdade em duas perspectivas, desde a moral - ética - e desde a incipiente teoria política e, finalmente, a relação entre razão e fé, reflexão que se inicia e se mantém sob a perspectiva da Teologia, porém cada vez mais abrindo espaço para o exercício da razão que contempla outras esferas e temas, questionando inclusive os critérios de "autoridade", incontestável até esse momento.

Quanto aos aspectos mais destacados nos novos "centros de saber" podem ser indicados os seguintes:

- A permanência de disciplinas como a Teologia nas suas vertentes bíblica, dogmática e mistica; a Gramática: principalmente em Chartres e a Dialéctica lógica - introduzida no trivium, mas que no seu desenvolvimento leva à afirmação de um método que será conhecido como escolástica.

3 LE GOFF, J. Os intelectuais na Idade Média. Lisboa: Gradiva, 1984, p. 18. 
- A cunhação de uma linguagem técnica de termos, tais como: mens, spinitus, anima, substancia, subsistência, species, ideia, etc., que permanecerão na linguagem de filósofos como Bacon, Descartes, Espinoza, Leibniz, etc.

- A renovação metodológica que marca outro dos pontos álgidos das escolas catedralícias e/ou capitulares.

No processo de sistematização do ensino deve destacar-se o papel dos compiladores e dos enciclopedistas, que preparam uma série de compêndios ou antologias, recolhendo e ordenando a doutrina dos Santos Padres e dos clássicos em forma de sentenças.

O exemplo mais destacado encontra-se em Pedro Lombardo, cujo Livro das sentenças chegou a ser o manual básico das faculdades de Teologia do século XIII. Vale a pena lembrar que esta obra divide-se em 4 livros: $01^{10}$ dedica-se a Deus, $\circ 2^{\circ}$ às criaturas, $\circ 3^{\circ}$ ao homem, à salvação e às virtudes e $04^{\circ}$ trata dos sacramentos. A organização do mesmo, com espaço próprio para "as criaturas" e "o homem" fala por si mesmo da nova perspectiva do saber.

O processo didático-pedagógico seguido nas escolas passava pela lectio (letra); pelo significado (sentido) com ajuda da Gramática e pela exposiçãoexplicação (quaestio-disputatio) que apresentava as diferentes dimensões do problema até chegar à sentença ou conclusão definitiva.

A transmissão do saber, usufruido pelos intelectuais do século XII, tem a sua continuidade no século seguinte, do desenvolvimento das formulações embrionárias à maturidade de propostas e soluções nas grandes sumas, de Guilherme de Alvenia a Duns Escoto, passando por Alberto Magno e Tomás de Aquino. O novo saber não se apóia somente na competência das autoridades, mas também na riqueza dos novos recursos intelectuais e na avalanche de novas fontes, traduções filosóficas e científicas de origem árabe que permitem o contato com Avicena, Averroes e Maimônides, preparando e facilitando o conhecimento progressivo e completo de Aristóteles. Um dos motores que impulsionou esta direção veio do mundo árabe que providenciou uma nova forma de aproximação à natureza.

O início do século XIII é marcado por uma organização mais rigorosa dos estudos que unido à licentia docendi desembocará na constituição das Universidades e, dentro delas, das Faculdades.

Nesse novo contexto, a Faculdade de Artes, dedicada quase exclusivamente aos estudos filosóficos, ocupará um lugar de destaque, primeiro pela sua conđição destinada à formação básica que contribui para elevar o nível cultural da população, embora nem todos atinjam o grau superior da Teologia e, em segundo lugar, porque nela se propiciam os estudos de filosofia natural, da metafísica e da filosofia moral que vão adquirindo autonomia, sem perder de vista a sua função de serviço à Teologia.

Em resumo, ao chegar à instituição das Universidades, o saber tinha percorrido novos caminhos: o estudo da natureza, que da observação direta da mesma passa à experimentação e uma nova visão de homem que vai do homem cristão ao homem natural retomando, inclusive, São Paulo; se o cristão se pautava pela fé, o homem natural o fará pela sua humanidade. 


\section{Organização dos centros de saber}

É a partir do século XII quando se pode falar propriamente do "intelectual" cujo conceito vai unido ao renascimento urbano. ${ }^{4} \mathrm{E}$, conseqüentemente, neste momento situa-se a origem dos centros intelectuais, com a fundação de escolas urbanas e capitulares. Porém, estas escolas mantêm ainda um sentido ambíguo, tanto pelo seu conteúdo como pelo seu significado. Se tivermos que realizar uma classificação por grupos ou categorias de escolas, estas poderiam ser agrupadas da seguinte forma: $1^{2}$ como lugar de ensino, localizando-se nos mosteiros, colegiatas e catedrais; $2^{\circ}$ pelo contexto dos ensinamentos impartidos, mestres, espírito, tradições, programas e métodos - Chartes, Laon ou Abelardo são exemplos deste tipo; e em 3 o lugar as caracterizandas tanto pelo lugar como pelos mestres e doutrinas que nelas se cultivam, sendo que o exemplo mais característico pode ser encontrado na escola de São Victor de Paris, que aglutina lugar acadêmico, homens e idéias.

Na passagem do século XII para o XIII, caberia outra classificação: escolas monásticas, escolas urbanas e escolas universitárias.

As monásticas organizam-se em volta da Biblioteca - Scriptorium. A base do seu ensino centrava-se na lectio divina, visam uma aprendizagem pacifica que prepare para a contemplação, nelas não se discute, originando-se uma certa suspicácia com relação às novidades, à toda organização autônoma e à ampliação dos quadros de saber. Um digno representante seria São Bernardo.

Nas escolas capitulares, sob o clero secular, a figura central é a do scholasticus que detém o cargo de chantre: organizador do culto, de chanceler: responsável pela formação dos futuros clérigos e, sobretudo, a de magister scholarum: organizador do ensino entre cujas funções está a de bibliotecánio e arquivista. Estas escolas oferecem uma nova perspectiva, já que nelas há espaço para a controvérsia.

A necessidade de mestres para novas escolas, unida a uma demanda progressiva de escolas, leva à instauração da licentia docendi, ou permissão para ensinar, competência inicialmente do scholasticus, que é quem a confere.

No fim do século XII a licentia docendi é universalmente reconhecida, tendo diferentes modalidades no seu exercício e sendo o caminho pelo qual se continua o monopólio do clero no ensino. A dura experiência de Abelardo, tendo alternativamente reconhecida ou cassada a sua licença, é o melhor exemplo das tensões para manter esse monopólio, e ao mesmo tempo revela a tendência à autonomia progressiva do saber. O papa Alexandre III (1159-1181), discipulo de Abelardo, introduzirá novas disposições sobre a licentia docendi, abrindo caminho às escolas autônomas.

A passagem das escolas urbanas para as universidades acompanha a evolução, compreensão e aplicação da licentia docendi, assim como a transformação do cargo de scholasticus, que perde autoridade para o papado; o cerne desta passagem está na autoridade capaz de outorgá-la. E, entre os elementos que aceleram e definem esta mudança caberia destacar os seguintes:

4 LE GOFF, J. Os intelectuais na Idade Média, op. cit. SANTIAGO OTERO, H. Fé e Cultura en la Edad Media. Madrid: C.S.I.C., 1988. - VERGER, J. História das Universidades. São Paulo: UNESP, 1996. 
- o maior número de mestres como "agregados";

- o aumento do prestígio de alguns mestres, diminuindo a importância das escolas capitulares;

- a formação de corporações de mestres e escolares para garantir os seus direitos frente ao chanceler e os Capitulos;

- a orientação e opção dos estudantes para as escolas livres;

- a ampliação e modificação progressiva dos programas no interior das próprias escolas unida à emancipação progressiva dos homens de estudo.

As Universidades de Paris (1200-1215) e Oxford (1200-1214), situam-se claramente nesse processo, sendo mais problemático determinar a origem eclesiástica de Bolonha (1190-1230) já anteriormente sob a proteção de Frederico Barba-Ruíva desde 1155; lembrando ainda que em Nápoles, Frederico II tinha fundado um centro de estudos que para alguns historiadores aparece como a primeira universidade do Ocidente. ${ }^{5}$

A escola de Nápoles, fundada por um poder exclusivamente laico, e a de Bolonha permitem dirigir o nosso olhar para os "centros de saber" dos países meridionais ou mediterrâneos, entre os que se situa o "Estudio General" - Universidade - teoricamente idealizado por Alfonso X O Sábio, nas Siete Partidas e que define e caracteriza as universidades na Península Ibérica, inseridas no processo geral das origens da instituição universitária.

\section{Alfonso X O Sábio e a Escola de Toledo}

Antes, porém, de entrar na análise do texto alfonsino, é preciso retomar o tema dos "centros de saber". É difícil estabelecer um paralelismo entre as instituições culturais da Espanha e o resto da Europa antes do século XIII, tanto pela exigüidade de documentos disponíveis, como pela falta de estudos parciais. Mas, como ignorar Toledo como centro de saber, quando os intelectuais do Norte a colocam como referência obrigatória de renovação e ciência? Até que ponto se lhe pode negar uma primazia ao lado de Paris ou Chartres? Como explicar a sua omissão na historiografia, reduzida apenas a uma função de mediação? São questões sugeridas com a leitura de testemunhos como o de Morley:

"A paixäo pelo estudo afastou-me de Inglaterra. Fiquei muito tempo em Paris. Aí, apenas vi
selvagens instalados nas suas cátedras escolares com uma grave autoridade [...]. A sua ig-
norância obrigava-os a uma posição de estátua [...] Tendo compreendido a situação, refleti
nos meios de escapar a tais riscos [...] Por isso, como é em Toledo que nos nossos dias, o
ensino dos árabes, que é constituído quase inteiramente pelas artes do quadrivium, é dis-
pensado às multidōes, apressei-me a partir para lá a fim de escutar as lições dos mais sá-
bios filósofos do mundo. Chamado por alguns amigos e convidado a regressar de Espanha,
vim para Inglaterra com uma preciosa quantidade de livros. Dizem-me que nestas regiões
se desconhece o ensino das artes liberais, que Aristóteles e Platão estão votados ao mais
profundo esquecimento [..]. Foi grande a minha dor e, para nảo ficar como um grego sozi-
nho entre romanos, pus-me a caminho em busca de um lugar onde pudesse ensinar e pro-
mover o desenvolvimento desse gênero de estudos."”

SANTIAGO OTERO, H. Fé y Cultura... op. cit., p. 162.

6 MORLEY, Daniel. In Le Goff, J. Os inteletuais na Idade Média, op.cit. p. 23. [Pierre Riché em Écoles et enseignement daris le haut Moyen-Âge - Paris, 1979 apenas faz uma referência a Toledo]. 
Toledo, herdeira da riqueza cultural do mundo árabe em Al-Andalus, é o centro que recolhe a experiência de Córdoba. Antes da sua conquista pelos cristãos, Yahya al Ma'mum (1037-1074) tinha feito de Toledo um centro intelectual e artístico de primeira ordem. Entre os árabes o ensino abrangia disciplinas religiosas, lingüústicas e ciências da razão dando-se prioridade às disciplinas científicas e literárias.

Said al-Andalusi no Livro das categorias das nações (1068) - Kutab Tabakat al-uman - indica que em Toledo destacavam-se os estudos de Astronomia; um dos seus discípulos, conhecido como Al Zarzali, mestre por sua vez, lidera um grupo de estudiosos; o fruto do seu trabalho são Las Tablas Toledanas, traduzidas por Gerardo de Cremona, no século XII.

A conquista de Toledo (1085) por Alfonso VI abre o caminho para a inserção da Espanha no circuito da Cristandade e, em Toledo, com a colaboração do bispo borgonhês Raimundo, favorece a concentração de sábios cristãos, judeus e árabes que fogem do rigorismo dos almohadas africanos. Os primeiros frutos do trabalho destes sábios, especializando-se progressivamente nas traduções, converterão a cidade em centro de atração, de transmissão e de saber, referência obrigada dos sábios do Norte do Ocidente, como vimos anteriormente.

Santiago-Otero chamou a atenção para um documento sobre a atividade escolar na vila de Toledo. Trata-se da obra Virgilii cordubensis philosofia, cuja versão latina datada de 1290 e depositada no Arquivo da catedral de Toledo, é apresentada pelo seu autor - ou pseudo autor Virgilio - como tradução de um original árabe. Ele se diz contemporâneo de Avicena (m.1037) mas também de Averroes (m.1198). Apesar do seu caráter apócrifo revela o ambiente intelectual da escola de Toledo; no começo da obra, afirma-se a importância cultural da mesma nestes termos:

"Havia desde muito antigo na vila de Toledo, cursos de todas as disciplinas, principalmente de Filosofia, a Escola estava situada fora da vila. Todos os filósofos toledanos, em número de doze, assistiam ao curso de filosofia; os cartagineses, os sevilhanos, os cântabros, os marroquinos e muitos outros vindos de diferentes lugares para estudar lá."?

Indicam-se não só os nomes dos filósofos, mas as suas especialidades: astrologia, nigromancia, piromancia e geomancia, assim como outras ciências; incluindo-se ainda um calendário escolar justificando os períodos de início e fim das aulas.

Antes, pois, de Alfonso X O Sábio, Toledo estava consagrada como centro intelectual, cuja especialidade eram as traduções - árabe, grego e latim - por meio de um sistema próprio e pela ação de equipes mistas nas quais colaboravam cristãos, árabes e judeus. ${ }^{8}$

Esta experiência será estimulada e continuada por Alfonso X que se interessa por tudo, traduz tudo, não só Filosofia, mas Matemática, Física, Medicina, Astro-

7 Apud SANTIAGO-OTERO, H. Transmissions des savoirs à Tolède à l'époque de la Reconquête. In Fé Y Cultura en la Edad Média. Madrid: C.S.I.C., 1988. p. 191 - 204.

8 MENÉNDEZ Pidal, Gonzalo. Como trabajaron las escuelas alfonsíes. In Nueva Revista de Filologia Hispánica. Mexico: Escuela de Mexico - Harvard University, 1951, p. 363-380. BRASA DÍEZ, M. Alfonso X el Sabio y los traductores españoles. In Cuadernos Hispanoamericanos, 410. Madrid: ICI, 1984, p. 21-33. 
logia, formando sua própria equipe de colaboradores e reforçando um dos aspectos das escolas peninsulares, o seu caráter laico, iniciando ainda uma nova tendência; a partir dele começa-se a traduzir e escrever em romance.

Duas etapas podem ser identificadas sob a égide do rei Sábio em Toledo. A primeira de 1250 a 1260 , quando se trabalha segundo o modelo tradicional toledano, cuja contribuição principal é a das traduções. E uma segunda etapa, a partir de 1260, quando, mais que traduções, se procuram fontes para compor depois obras originais - As Crônicas, As Cantigas, As Tábulas Alfonsinas - com uma verdadeira preocupação cientifica.

Se as obras produzidas no século XII em Toledo, embora fiéis ao conteúdo das fontes, apresentam um latim grosseiro e descuidado pela sua literalidade, no século XIII percebe-se uma maior qualidade nas traduções para o latim, cobrando cada vez mais importância a língua vernácula.

A vigência das obras de Alfonso X pode ser constatada pela reprodução de algumas delas, como as Tabulae Alphonsi, impressas em Veneza (1483) e em Leipzig (1580). Os cientistas as utilizavam, Copérnico em 1500 trabalha sobre elas deixando constância nas anotações do seu punho e letra.

A primeira vinculação de Alfonso X com a cidade de Toledo é constituída pelo fato de ter nascido nela. Já como rei, confirma e aumenta os privilégios outorgados a diferentes segmentos da sociedade toledana, cavaleiros, clérigos, moradores e vizinhos da cidade.

Toledo foi, por outro lado, durante o seu reinado, cenário de transcendentais acontecimentos e projetos, tanto políticos quanto culturais, que justificam, de certo modo, o amor que Alfonso dedicou à cidade do Tejo junto com Sevilha e Múrcia, cidades nas quais estabeleceu também "Estudos Gerais".

Em Toledo celebraram-se Cortes em 1254 e 1299, receberam-se embaixadas e assinaram-se tratados. Mas é sobretudo o lugar onde o rei se dedica a sua tarefa preferida: a cultura. $\mathrm{E}$, se é certo que Alfonso se servia de colaboradores, também o é que o próprio rei participava diretamente na direção e redação de suas obras. $\mathrm{Na}$ hora do trabalho mais delicado não delegava a ninguém, pois a seleção dos livros mais verdadeiros ou melhores era dele, como também a responsabilidade de selecionar todos os fechos destacados ou de solicitar uma nova tradução, quando não ficava satisfeito com a que se the apresentava. Ninguém melhor do que Don Juan Manuel, seu sobrinho, para caracterizar a sua atuação:

“[...] ninguém poderia dizer mais nem tão bem como ele [...] primeiro, pelo grande entendimento que Deus lhe concedeu, segundo, pelo grande empenho - talante - que tinha para fazer coisas nobres e proveitosas. $\mathrm{E}$ ainda porque tinha na sua corte muitos mestres de ciências e de saberes aos quais favorecia muito para levar adiante o saber e para enobrecer seus reinos. Sobre todas as ciências fez muitos livros e todos bons. Porque dedicava muito tempo ao estudo das matérias com as quais queria compor alguns livros. Assim residia em alguns lugares um, dois ou mais anos. E, segundo dizem os que viviam sob a sua proteção, falavam com ele os que queriam e quando ele queria, havendo assim espaço para estudar no que ele queria fazer para si mesmo e ainda para determinar as coisas dos saberes que ele mandava ordenar aos mestres e aos sábios que tinha para isto na sua corte."9

9 Don Juan Manuel. Crónica abreviada. In Obras Completas de (Blecua, J. M.: Ed.) Madrid: Gredos, 1983, p. 575. 
Em Toledo registram-se as estadias mais prolongadas do monarca (de 1258 a 1260). Datas importantes relacionadas com as atividades culturais do rei que faz da cidade "metro e medida", quer dizer o ponto zero, dos cálculos astronômicos aqui realizados sob sua encomenda, como seria metro e medida da língua castelhana segundo pode ser constatado nas ordenanças das Cortes:

“[... que se d'agora em diante em alguma parte do Reino houvesse diferença na compreensão de algum vocábulo castelhano antigo [...] devia-se recorrer com ele a esta cidade [...] e ser comparado com o significado e forma aqui dadas ao tal vocábulo, por ter a nossa língua, nesta cidade, mais perfeição que em outra parte."10

Nos palácios de Galiana, local do nascimento do rei, reunem-se e trabalham os redatores das Partidas, e não é de estranhar que os sonhos imperiais do Alfonso surjam nesta cidade, antiga sede da corte visigótica, "cidade imperial" desde os tempos de Alfonso VII. ${ }^{11}$

\section{Os centros de saber nas Sete Partidas}

Confluem, pois, em Alfonso X, uma tradição especificamente hispana, um conhecimento do que acontece e se demanda na Cristandade, engajado ativamente nela como se manifesta pela sua candidatura ao Império è uma posição decidida de compromisso com o saber que devia repercutir na colectividade por ele presidida, desde uma perspectiva organizativa de conceitos universais.

Neste sentido, o saber, os centros de saber, como o resto das atividades que atingem a coletividade ocupará um espaço importante na tentativa de organizar esta sociedade como um todo. Assim sendo, os sábios, o papel deles na sociedade e os meios de transmitir o conhecimento estarão incluídos na legislação prática, no Direito.

Do ponto de vista de uma história comparada da legislação, a obra de Alfonso $\mathrm{X}$ não representa algo excepcional, insere-se no movimento de codificação que de 1231 até 1281 se espalhou por toda a Europa, entendendo por codificação: "a coleção de preceitos jurídicos elevados a lei no seu conjunto". Foram iniciadores deste processo - segundo Wolf - Frederico II com o Libri Augustalis (1231) no reino de Sicilia; Gregorio IX com o Libri Extra (1234) para a Igreja; Jaime I de Aragão com o Fori Valenciae (1238/39) e o Fori Aragonum (1247) e Valdemar Sejr em Dinamarca com Iyske Lou (1241), sendo Aragão, após Sicilia e Dinamarca, o terceiro país que possui um código que chegou até nós. ${ }^{12}$

10 Pedro de Alcocer. Histonia o Descripción de la Imperial ciudad de Toledo, 1554. Apud BENTTO RUANO, E. In Alfonso X el Sabio, vida, obra y época. Madrid: SEEM, 1989, p. 255.

11 Um dos empenhos politicos de Alfonso foi a pretensão ao trono imperial como descendente de Beatriz de Suábia. Aspiração esta que contribuiu para o seu desprestígio e fracasso político no interior do reino de Castela.

12

WOLF, Amin. El movimiento de legislación y de codificación en Europa en tiempos de Alfonso el Sabio. In Alfonso $X$, el Sabio, vida, o bra y época. Actas del Congreso Internacional... Madrid: SEEM, 1989. p. 31-37. Para o autor os legisladores mencionados tiveram todos uma relação de parentesco ou afinidade através da Casa de Barcelona. 
Em 1251 iniciou-se em Portugal a série de Leis gerais de Afonso III; e em Castela, na corte de Alfonso O Sábio, elabora-se o Fuero Real (1252/55), e a primeira redação do Libro de las Leyes (1256/58), conhecida posteriormente como El Especulo (1255), passo prévio às Siete Partidas. Nem a França nem a Inglaterra chegaram a possuir uma codificação coerente mas uma série de Ordenanças (S. Luís: 1245), Provisões de Oxford (1258) e os Estatutos (1267) de Eduardo I.

A preocupação legislativa ou codificadora dos monarcas ocidentais representa a tentativa dos mesmos de reger os seus reinos de uma maneira "moderna" por meio de uma legislação unificada. Esta tentativa de governo chocou em todas partes com a oposição dos barões e freqüentemente com as autoridades eclesiásticas. Supõe, também, a busca de cooperação entre o rei e os novos estamentos das cidades para se liberar da pressão e controle da nobreza, tentativa fracassada inicialmente que emerge, relativamente vitoriosa, na gênese dos Estados modernos.

Para acompanhar a inserção da obra legislativa do monarca castelhano interessa-nos, por outro lado, frisar as relações de familia e amizade pessoal mantidas entre Alfonso X e Jaime I, tanto como a sua colaboração política. ${ }^{13}$ Isto permite estabelecer um elo muito significativo no que se refere à legislação e ao Direito. $\mathrm{O}$ jurista que trabalha para Jaime I de Aragão, Vidal de Cañellas, apresentado nos documentos como consanguineus do rei, é de suma importância para a História da legislação européia. Este jurista estava em Bolonha em 1221, sendo discípulo de Raimundo de Peñafort, que de 1218 a 1221 ensinava nesta cidade como professor de Direito Canônico e foi encarregado por Gregónio IX de redatar o Liber Extra ou código canônico promulgado em 1234.

Este elo que relaciona as atividades legislativas de Alfonso X com Bolonha é importante, também, para compreender o caminho seguido na organização dos "centros de saber" tal como aparece no código das Sete Partidas.

Na Segunda Partida dedica-se o Título XXXI a este tema; a sua enunciação é a seguinte: Dos estudos (escolas) em que se aprendem os saberes, dos mestres e dos escolares, e compreende 11 apartados ou leis. ${ }^{14}$

O primeiro elemento a destacar é o lugar que ocupa o Título destinado ao estudo dentro da Segunda Partida. Na introdução da mesma se indica:

\footnotetext{
"Mostraremos nesta Segunda Partida o relativo à justiça temporal e daqueles que a devem manter. Primeiramente dos imperadores e dos reis que são as mais nobres e honradas pessoas a quem isto pertence mais que aos outros homens. E outrossim como devem governar suas terras e seus reinos e servir-se e aproveitar-se deles, e como devem ser para os seus povos, e os povos para eles. E, de cada uma destas razões diremos a seguir no lugar correspondente, segundo o mostraram os sábios entendidos, e como convém para que seja feito e guardado racionalmente."
}

13 ROBERT, I. - BURNS, S. J. (Org.) Los mundos de Alfonso el Sabio y Jaime el Conquistador. Razón y fuerza en la Edad Media. Valencia: Ed. Alfons el Magnánim, 1990.

14 ALFONSO X o Sábio. Las Siete Partidas del Rey Sábio don Alonso el nono [sic] nuevamente glosadas por el Licenciado Gregorio Lopez del Consejo Real de Indias de su Magestad. Salamanca. Año M.C.L.V. (Edição Facsimil) Madrid: Boletin Oficial del Estado, 1985. 3 vols. Todas as citações das Sete Partidas serão tiradas desta edição. 
Este sentido de serviço público e de competência laica não oferece lugar a dúvidas na concepção alfonsina com relação à responsabilidade sobre a educação e a cultura. Aspecto explicitado novamente na introdução do Título que nos ocupa o qual diz assim:

\begin{abstract}
"De como o Rei e o povo devem amar e guardar a terra onde vivem, povoando-a e defendendo-a dos inimigos dissemos amplamente nos titulos anteriores. E porque do conselho dos homens sábios todos os homens e as terras se aproveitam e se protegem e se guiam, queremos ainda no fim desta partida falar dos estudos e dos mestres e dos escolares, que se afanam por ensinar e aprender os saberes. E diremos primeiramente que coisa é estudo. $\mathrm{E}$ quantas são as formas dele e qual é a autoridade que o pode estabelecer. $\mathrm{E}$ como devem ser os mestres nos estudos, e em que lugar devem ser estabelecidos e que privilégios e honras devem ter os mestres e os escolares que leeem e aprendem quotidianamente. E depois falaremos dos estacionários que cuidam dos livros e de todos os homes-escola que pertencem ao Estudo Geral." 15
\end{abstract}

Parte, como se indica na introdução, da definição do que é o Estudo: corporação - ayuntamiento - de mestres e escolares [...] com vontade e desejo de aprender os saberes; tipos de escolas: "estudo geral" - universidade - e "particular" e da autoridade competente para instituí-las: o papa, o imperador ou o rei (Lei I).

Na lei II trata-se do lugar onde deve ser estabelecida a escola e da segurança de mestres e escolares. Tema que se complementa na lei V. Diz assim:

"De bom ar e de formosas saidas deve ser a vila onde se deseje estabelecer a escola para que os mestres que ensinam os saberes e os escolares que os aprendem vivam sadios nela e possam folgar e ter prazer na tarde, quando se levantarem cansados do estudo [...] e a vila deve ser rica de pão e vinho, e ter boas pousadas [...] os cidadãos do lugar [...] devem proteger e honrar os mestres e os escolares [...] e se (os oficiais) maliciosamente se levantam contra os escolares não querendo lhes fazer.justiça, os que isto fizerem devem ser exemplarmente castigados por ordem e vontade do rei" (Lei II).

O número de mestres, salários e formas de pagamento é tratado na lei III, determinando-se que deve haver tantos mestres quantas sejam as ciências; os salários serão estabelecidos pelo rei de acordo com a capacitação de cada um. E devem exercer a sua função bem e lealmente ensinando da melhor forma que eles puderem, completando o programa sem colocar substitutos; estando previstos os casos de doença ou morte dos mesmos (Lei IV).

O tema da organização como corporação de mestres e escolares é tratado na Lei VI, destacando-se aqui o aspeto de exceção que tem a corporação universitária:

"Os sábios antigos defenderam que não fosse feita corporação - ayuntamiento - e confraria de muitos homens nas vilas e nos reinos, porque disso segue-se mais mal que bem. Mas estabelecemos por direito que os mestres e os escolares possam fazê-la em Estudo Geral, porque eles se reúnem com a intenção de fazer o bem e porque são forasteiros e de lugares distantes $[. .$.$] é conveniente que todos se reúnam conforme o direito quando seja mister$ para os assuntos que fossem em favor dos seus estudos e para proteção de si mesmos" (Lei VI).

15 Ver Anexo. Apresenta-se nele o texto completo do Titulo XXXI dedicado aos estudos na Segunda Partida. 
Indica a necessidade de estabelecer um reitor, definindo as suas funções, entre outras a de vigiar e:

\begin{abstract}
"castigar e zelar para que os escolares não levantem bandos nem pelejas [...] que não façam desonra nem tropelias a ninguém. E procurar que não andem de noite, mas que fiquem sossegados nas suas pousadas para que possam estudar e aprender e fazer vida honesta e boa. Porque os estudos foram estabelecidos para isso e não para andar de noite nem armados nem metidos em pelejas e fazendo loucuras ou malvadezas em prejuízo de si mesmos" (Lei VI).
\end{abstract}

Outros aspectos organizativos são contemplados na Lei X, na qual se trata do oficio e das funções do bedel.

$\mathrm{Na}$ Lei VII trata-se da autonomia jurídica e do privilégio de ter juízes próprios, salvo em caso "de crimes de sangue", se o escolar fosse leigo.

Sobre o status - honras - que corresponde aos mestres se dá um destaque especial aos mestres de leis porque a lei é como fonte de justiça e o mundo aproveita-se dela mais do que de outra ciência. Indicam-se os privilégios que correspondem a esta categoria social. Em primeiro lugar o direito de ter nome de cavaleiros; em segundo, concedendo-se-lhes prioridade hierárquica diante de qualquer outro juiz; em terceiro lugar, se lhes concede acesso direto a reis e príncipes; e em quarto, que, depois de vinte anos de serviço, adquiram a honra de condes. Todos os mestres devem estar isentos de impostos, de ser convocados às armas ou de serem obrigados ao exercício de outro ofício sem o seu consentimento.

Quanto à concessão da licentia docendi, determina-se a necessidade de passar pelo exame correspondente no qual deve-se demonstrar o conhecimento, a capacitação docente e a boa fama, devendo, os examinandos, prestar juramento de que procederão bem e lealmente no ensino do seu saber, assim como ter garantia de que não barganharam fazendo presentes ou doações àqueles que thes outorgaram a licença, direta ou indiretamente, comprando o poder de serem mestres (Lei IX).

Dedica-se a última lei (XI) ao tema dos livros determinando que, nos "Estudos Gerais", deve haver estacionários (bibliotecários) que tenham postos de livros como modelo; frisando a necessidade de que toda escola deve ter bons livros e legiveis e verdadeiros de texto e de glosa para uso e copia dos estudantes. Esta responsabilidade sobre a qualidade dos livros cabe ao reitor, assim como a de nomear "bibliotecário" e estipular os preços para o seu uso.

A Inserção do Rei Sábio no contexto da sua época; a abertura e o conhecimento das mais variadas fontes quando elabora as suas obras; a abrangência dos aspectos considerados; o seu caráter laico e público com independência do poder ou controle eclesiástico e, finalmente, o sentido positivo de aplicação, como corresponde ao lugar ocupado por este tema no código das Sete Partidas, oferece uma das mais completas sinteses do que foi a instituição universitária no século XIII. Instituição, surpreendentemente, não tão distante da universidade que encontramos hoje, nem pelo seu espírito corporativo nem pelos tópicos aqui considerados: das ciências em si, dos mestres e escolares, da organização interna e suas relações com a comunidade, da docência, dos deveres e privilégios correspondentes à categoria dos intelectuais, já definida e delimitada na Idade Média. 


\section{ANEXO DOCUMENTAL \\ Las Siete Partidas. Alfonso X el Sabio ${ }^{16}$}

\section{SEGUNDA PARTIDA - Titulo XXXI - De los estudios, en que se aprenden los saberes, e de los maestros e de los escolares}

De como el Rey e el pueblo deuen amar e guardar la tierra en que biuen, poblandola e amparadola de los enemigos, diximos asaz complidamente, en los titulos ante deste. E porque de los omes sabios, los omes e las tierras e los Reynos se aprouechan, e se guardan e se guian, por el consejo dellos, por ende queremos enla fin desta partida fablar, de los estudios, e de los maestros, e de los escolares que se trabajan de amostrar e daprender los saberes. E diremos primeramente que cosa es estudio. $\mathrm{E}$ quantas maneras son del e por cuyo mandado deue ser fecho. $\mathrm{E}$ que maestros deuen ser los que tienen las escuelas enlos estudios e en que lugar deuen ser estabelecidos, e que provilegio e que honrra deuen auer los maestros, e los escolares que leen e aprenden cotidianamente. E despues fablaremos delos estacionarios que tienen los libros e de todos los omesescolas que pertenescen al estudio general.

\section{Ley I: Que cosa es estudio e quantas maneras son} del e por cuyo mandado deue ser fecho

Estudio es ayuntamiento de maestros e de escolares que es fecho en algun lugar, con voluntad e entendimiento de aprender los saberes. E son dos maneras del. La vna es a que dizen estudio general, en que ay maestros de las artes asi como de Gramatica, e de la Logica, e de la Retorica, e de la Aritmetica, e de la Geometria, e de la Astrologia. E otrosi en que ay maestros de Decretos, e señores de leyes. $\mathrm{E}$ este estudio deue ser establecido por mandado del Papa o de Emperador, o del Rey. L(a) II manera esla que dizen estudio particular que quiere tanto dezir como quando algun maestro muestra en alguna villa, apartadamente, a pocos escolares. $\mathrm{E}$ a tal como este, pueden mandar fazer perlado 0 concejo de algun lugar.

\section{Ley II: En que logar deue ser establecido el estudio e como deuen ser seguros los maestros}

De buen ayre e de fermosas salidas, deue ser la villa, do quisieren establecer estudio porque los maestros, que muestran los saberes, e los escolares que los aprenden, biuan sanos en el, e puedan folgar, e recebir plazer, en la tarde, quando se leuantaren cansados del estudio. Otrosi, deue ser abondada de pan e de vino, e de buenas posadas, en que puedan morar, e passar su tiempo, sin gran costa. Otrosi dezimos, que los cibdadanos de aquel logar do fuere fecho el estudio, deuen mucho guardar, e honrar, alos maestros e a los escolares, e atodas sus cosas. $\mathrm{E}$ los maestros que vienen a ellos, de sus lugares non los deue ninguno prender, nin embargar, por debda que sus padres deuiessen, nin los otros de las tierras donde ellos fuessen naturales. $\mathrm{E}$ avn dezimos, que por enemistad, nin por malquerencia, que algun ome ouiesse contra los escolares, o a sus padres: non les deuen fazer deshonrra, nin tuerto, nin fuerça. $\mathrm{E}$ porende mandamos, que los maestros e los escolares e sus mensajeros e todas sus cosas sean seguras, e atreguadas, en viniendo a las escuelas, e estando en ellas, e yendo a sus tierras. E esta segurança les otorgamos, por todos los logares, de nuestro señorio. E qualquier que contra esto fiziere, tomandole por fuerça, o robandole lo suyo, deue gelo pechar quatro doblado e si lo firiere, o deshonrrare, o matare, deue ser escarmentado cruelmente, como ome que quebranta nuestra tregua e nuestra segurança. Mas si por ventura,

16 Las Siete Partidas del Rey don Alonso el nono [sic], nuevamente Glosadas por el Licenciado Gregorio Lopez del Consejo Real de Indias de su Magestad. Salamanca. Año M.D.L.V. Edição Facsimil: Madrid, Boletin Oficial del Estado, 1985. 3 vols. Segunda Partida: Vol. I. 
los judgadores, ante quien fuesse fecha esta querella, fuessen negligentes en fazer les derecho, asi como sobredicho es, de lo suyo deuen pechar, e ser echados de los oficios por enfamados. E si maliciosamente se mouiessen contra los escolares, non queriendo fazer justicia, de los que los deshonmassen, o firiessen, o matassen, estonce, los oficiales que esto fiziessen, deuen ser escarmentados, por aluedrio del Rey.

\section{Ley III: Quantos maestros deuen ser en el estudio general e a que plazos deuen ser sus salarios e de como deuen ser pagados}

Para ser el estudio general complido, quantas son las sciencias, tantos deuen ser los maestros que las muestren, assi que cada vna dellas, aya vn maestro alo menos. Pero si para todas las sciencias, non pudiessen auer maestro, abonda que aya de Gramatica, e de Logica, e de Retorica, e de Leyes, e de Decretos. E los salarios de los maestros, deuen ser establecidos por el Rey, señalando ciertamente quanto aya cada vno segun la sciencia que mostrare, e segun que fuesse sabidor della. E aquel salario que ouiere de auer cada vno dellos, deuen gelo pagar en tres vezes. La vna parte les deuen dar luego que començaren el estudio. La segunda por la pascua de resurrecion. La tercera, por la fiesta de sant Iohan bautista.

\section{Ley IV: En que manera deuen los maestros mostrar}

\section{a los escolares los saberes}

Bien e lealmente deuen los maestros mostrar sus saberes a los escolares, leyendo los libros, e faziendo gelo entender lo mejor que ellos pudieren. $\mathrm{E}$ de que conmençaren a leer, deuen continuar el estudio, toda via, fasta que ayan acabado los libros, que conmençaran. $E$ en quanto fueren sanos, non deuen mandar a otros, que lean, en logar dellos, fueras ende, si alguno dellos mandasse a otro leer alguma vez para le honrrar, e non por razon de se escusar el del trabajo del leer. Mas si por ventura, alguno de los maestros enfermasse, despues que ouiesse començado el estudio, de manera, que la enfermedad fuesse tan grande e tan luenga, que non pudiesse leer en ninguna manera, mandamos que le den el salario, tan bien como si leyesse. E si acaesciesse que muriesse de la enfermedad, sus herederos deuen auer el salario tambien como si leyesse todo el año.

\section{Ley V: En que logares deuen ser ordenadas las escuelas} de los maestros e de los escolares

Las escuelas del estudio general deuen ser en vn logar apartado de la villa, las vnas cerca de las otras. Porque los escolares, que ouieren sabor de aprender, ayna puedan tomar dos liciones o mas si quisieren, e en las cosas que dubdaren puedan preguntar los vnos alos otros. Pero deuen ser las vnas escuelas tan apartadas de las otras, que los maestros non se embarguen oyendo los vnos lo que leen los otros. Otrosi dezimos, que los esolares deuen guardar, que las posadas, o las casas, en que moraren los vnos, non las loguen los otros en quanto en ellas moraren e ouieren voluntad de morar en ellas. Pero si entendiesse vn escolar, que la casa en que morasse otro, non auia voluntad, de fincar mas, de fasta el plazo que la auia alogada, si el ouiesse sabor de la auer, deue le preguntar al otro, que la tiene, si ha voluntad de fincar en ella del plazo en adelante. E si dixere que non, estonce puede la logar, e tomar para si, e non de otra guisa.

\section{Ley VI: Como los maestros e los escolares pueden fazer ayuntamiento e hermandad entresi, e escoger vno que los castigue}

Ayuntamiento e cofradias de muchos omes, defendieron los sabios antiguos, que non se fiziessen en las villas, nin en los Reynos, por que dello se leuanta mas mal que bien. Pero tenemos por derecho, que los maestros e los escolares puedan esto fazer, en estudio general, por que ellos se ayuntan con entencion de fazer bien, e son estraños, e de logares 
departidos. Onde conuiene que se ayunten todos a derecho, quando les fuere menester en las cosas, que fueren a pro de sus estudios, e a amparança de si mismos, e de lo suyo. Otrosi pueden establecer de si mismos un mayoral sobre todos, que llaman en latin rector del estudio al que obedezcan, en las cosas conuenibles, e guisadas, e derechas. E el rector deue castigar, e apremiar a los escolares, que non leuanten vandos nin peleas con los omes de los logares do fueren los escolares, ni entre si mismos. E que se guarden de todas guisas, que non fagan deshonrra, nin tuerto a ninguno. $\mathrm{E}$ defender les que non anden de noche, mas que finquen sosegados en sus posadas, e que punen de estudiar, e de aprender, e de fazer vida honesta, e buena. Ca los estudios para esto fueron establecidos, e non para andar de noche, nin de dia armados, trabajandose de pelear, e de fazer otra locura, o maldad, a daño de si, e estoruo de los lugares do biuen. E si contra esto fiziessen, estonce, el nuestro juez, los deue castigar, e endereçar, de manera que se quiten de mal, e fagan bien.

\section{Ley VII: Quales juezes deuen judgar a los escolares}

Los maestros que muestran las sciencias en los estudios, pueden judgar sus escolares en las demandas, que ouieren vnos con otros, e en las otras que los omes les fiziessen, que no fuessen sobre pleyto de sangre e non les deuen demandar nin traer a juyzio delante de otro alcalde, sin su plazer dellos. Pero si les quissieren demandar, delante de su maestro: en su escogencia es de responder a ella o delante del obispo del logar, o delante del juez del fuero, qual mas quisiesse. Mas si el escolar, ouiesse demanda contra otro que non sea escolar, estonce deue le demandar derecho, ante aquel que puede apremiar al demandado. Otrosi dezimos, que si el escolar es demandado, ante el juez del fuero, e non alegare su priuillejo, diziendo que non deue responder, si non adelante de su maestro, o ante el obispo, assi como sobredicho es, si respondiere llanamente a la demanda, pierde el priuillejo que auia, quanto en aquellas cosas sobre que respondio, e deue yr por el pleyto adelante, fasta que sea acabado, por aquel juez ante quien lo començo. Mas si por ventura, el escolar se quisiesse ayudar de su priuillejo, ante que respondiesse a la demanda, diziendo que non queria, nin deue reponder, si non ante su maestro, o delante del obispo, e el le apremiasse, e le fiziesse responder, a la demanda, estonce el que auia la demanda contra el, deue perder porende, todo el derecho, que auia, en la cosa que le demandaua. $\mathrm{E}$ el juez que assi lo apremiasse, deue auer pena porende por aluedrio del Rey, fueras si el pleyto fuesse de justicia, o de sangre que fuesse mouido, contra el escolar, que fuesse lego.

\section{Ley VIII: Que honrras señaladas deuen auer los maestros de las leyes}

La sciencia de las leyes es como fuente de justicia, e aprouecha se della el mundo, mas que de otra sciencia. E porende los Emperadores que fizieron las leyes, otorgaron priuillejo a los maestros de las escuelas, en quatro maneras. La vna, ca luego que son maestros han nome de maestros e caualleros, e llamaron los Señores de leyes. La segunda es que cada vegada que el maestro de derecho, venga delante de algun juez que este judgando, deue se levantar a el, e saluarle: e rescebir le, que sea consigo, e si el judgador contra esto fiziere, pone la ley por pena, que le peche tres libras de oro. La tercera, que los porteros de los Emperadores, e de los reyes, e de los principes, non les deuen tener puerta, nin embargar les, que non entren ante ellos quando menester les fuere. Fueras ende, a las sazones que estuuiessen en grandes poridades. $\mathrm{E}$ aun estonce deuen gelo dezir, como estan tales maestros a la puerta, e preguntar si les mandan entrar o non. La quarta es, que sean sotiles, e entendidos, e que sepan mostrar este saber, e sean bien razonados, e de buenas maneras, e despues que ayan veynte años tenido escuela de las leyes, deuen auer honrra de condes. $\mathrm{E}$ pues que las leyes, e los Emperadores, tanto los quisieron honrrar, 
guisado es que los Reyes los deuen mantener en aquella misma honrra. E porende, tenemos por bien que los maestros sobredichos, ayan en todo nuestro Señorio, las honrras, que de suso diximos, assi como la ley antigua lo manda. Otrosi dezimos, que los maestros sobredichos, e los otros que muestran los saberes en los estudios, en las tierras del nuestro Señorio, que deuen ser quitos de pechos, e non son tenidos de yr en hueste, nin en caualgadda, nin de tomar a otro oficio, sin su plazer.

\section{Ley IX: Como deuen prouar al escolar que quiere ser maestro ante que le otorguen licencia}

Discipulo deue ante ser el escolar que quier auer honrra de maestro. E desque ouiesse bien aprendido, deue venir ante los mayorales de los estudios, que han poder de les otorgar la licencia para esto. E deuen catar en poridad, ante que lo otorguen, si aquel que la demanda, es ome de buena fama, o de buenas maneras. Otrosi, deue dar algumas leciones, de los libros de aquella sciencia, en que quier começar. E si ha buen entendimiento del texto, e de la glosa, de aquella sciencia, e ha buena manera, e desembargada lengua para mostrarla. E si responde bien a las questiones e a las preguntas que le fizieren, deuen le despues otorgar publicamente honrra para ser maestro, tomando jura del, que demuestre bien e lealmente la su sciencia, e que nin dio nin prometio a dar ninguna cosa, a aquellos que le otorgaron la licencia, nin a otro por ellos, por que le otorgassen poder de ser maestro.

\section{Ley X: Como todos los escolares del estudio ayan vn mensajero a que llaman bedel e qual es su oficio}

La vniversidad de los escolares, deue auer su mensajero, a que llaman en latin bidellus. E su oficio deste a tal non es si non andar por las escuelas, pregonando las fiestas por mandado del mayoral del estudio, e si acaesciesse que algunos quieren vender libros o comprar, deuen gelo dezir. $\mathrm{E}$ assi deue el andar preguntando e diziendo que quien quiere tales libros, que vaya a tal estacion, en que son puestos, e de que sopiere quien los quiere vender e quales quieren comprar, deue traer la trujamania entre ellos lealmente. $E$ otrosi pregone este bedel, de como los escolares, se ayunten en vn lugar, para ver e ordenar algunas cosas de su pro comunalmente, o por fazer esaminar a los escolares, que quieren fazer maestros.

\section{Ley XI: Como los estudios generales deuen auer estacionarios, que tengan tiendas de libros para exemplarios}

Estacionarios ha menester que aya en todo estudio general, para ser complido, que tenga en sus estaciones, buenos libros e legibles e verdaderos de texto e de glosa, que los loguen alos escolares para fazer por ellos libros de nueuo, o para emendar los que touieren escritos. $\mathrm{E}$ tal tienda o estacion como esta, non la deue ninguno tener, sin otorgamiento del rector del estudio. $\mathrm{E}$ el rector, ante que le de licencia para esto, deue fazer esaminar primeramente, los libros de aquel que deuia tener la estacion, para saber si son buenos, e legibles, e verdaderos. $E$ aquel que fallare, que non tiene tales libros, non le deue conferir que sea estacionario, nin logue a los escolares los libros, amenos de ser bien emendados primeramente. Otrosi deue apreciarle el rector, con consejo del estudio, quanto deue recebir el estacionario por cada quaderno, que prestare a los escolares, para escreuir o para emendar sus libros. $\mathrm{E}$ deue otrosi recebir, buenos fiadores del, que guardara bien, e lealmente, todos los libros, que a el fueren dados, para vender, que non fara engaño ninguno. 